\title{
Synergistic effect of the L-tryptophan and kynurenic acid with dipyrone or paracetamol in mice
}

\author{
Nayrton Flávio Moura Rocha a,*, Emiliano Ricardo Vasconcelos Rios a , Alyne Mara Rodrigues Carvalho ${ }^{\mathrm{a}, \mathrm{b}}$, \\ Leonardo Vasconcelos Freire ${ }^{a}$, Marília Leite Dias ${ }^{a}$, Marta Maria de França Fonteles ${ }^{a, b}$, \\ Francisca Cléa Florenço de Sousa ${ }^{a}$
}

${ }^{a}$ Department of Physiology and Pharmacology, Universidade Federal do Ceará, CEP: 60430-270, Brazil

${ }^{\mathrm{b}}$ Department of Pharmacy, Universidade Federal do Ceará, CEP: 60430-370, Brazil

\section{A R T I C L E I N F O}

\section{Article history:}

Received 6 April 2013

Received in revised form 24 June 2013

Accepted 3 July 2013

Available online 16 July 2013

\section{Keywords:}

Dipyrone

Paracetamol

L-Tryptophan

Kynurenic acid

Nociception

Synergism

\begin{abstract}
A B S T R A C T
Purpose: Our great interest in this work was study the synergism between L-tryptophan and dipyrone or paracetamol as well as the interaction of kynurenic acid (L-tryptophan metabolite) and these analgesics agents utilizing a robust methodology.

Methods: We performed the writhing test induced by acetic acid in mice to evaluate the antinociceptive effect of the treatments isolated and combined (p.o. and i.p.). Dose-response curves were constructed and the values of $\mathrm{ED}_{50}$ for treatment alone and combined were statistically compared. In addition, isobolographic analysis was performed and the experimental values were compared with the theoretical values for simple additive effect.

Results: The combined treatment with L-tryptophan and dipyrone or paracetamol reduced significantly the $\mathrm{ED}_{50}$ of these analgesics when compared to the isolated treatments. L-tryptophan alone has no antinociceptive effect. L-Tryptophan increases the central amount of 5-HT and the synergism with dipyrone is antagonized by the 5-HT depletion. The kyna has an antinociceptive dose-related effect and a synergistic interaction with dipyrone and paracetamol verified by isobolographic analyses and confirmed by experimental values of $\mathrm{ED}_{50}$ of combined treatments were statistically lower than theoretical calculated values for simple additive effect. Melatonin antagonist receptor attenuates the antinociceptive synergism between L-tryptophan and dipyrone.

Conclusion: Our results demonstrate that the increased 5-HT amount on the central nervous system is not per se capable to induce antinociception. The L-tryptophan interacts synergistically with dipyrone and paracetamol both orally and by i.p. route. This effect is dependent on the biotransformation of L-tryptophan to 5-HT and involves kynurenic acid and melatonin receptors.
\end{abstract}

(c) 2013 Elsevier Ireland Ltd. All rights reserved.

\section{Introduction}

Dipyrone (dipirone or metamizol) and L-tryptophan are two substances historically associated with pain relief. The use of dipyrone is controversial due to its association with serious toxic effects, particularly in the United States and other developed countries [1-3]. However, several studies have demonstrated the safety of the dipyrone in different populations [4-8]. Available in countries such as Russia, Israel, Spain, Mexico and India, dipyrone in Brazil is an over-the-counter drug defined as safe by the Brazilian Public Health Surveillance System, Agência Nacional de Vigilância Sanitária (ANVISA) [9-11].

\footnotetext{
* Corresponding author. Address: Department of Physiology and Pharmacology, Universidade Federal do Ceará, Cel. Nunes de Melo 1127 Street, CEP: 60430-270, Fortaleza, Ceara, Brazil. Tel.: +55 (85) 3366 8337; fax: +55 (85) 33668333.

E-mail address: nayrtonf@hotmail.com (N.F.M. Rocha).
}

Paracetamol as an analgesic of proven efficacy but higher doses are associated with serious toxic effects. It is hepatotoxic for humans at doses above $125 \mathrm{mg} / \mathrm{kg}$ [12] and its overdose, both intentional and unintentional, remains a significant public health concern with an annual average (2000-2006) of 33.520 hospitalizations in the US Improving efficacy without increasing adverse effects, or decreasing adverse effects without loss of efficacy are the main therapeutics goals of the combination of analgesic drugs. Besides, the decrease of the availability of these drugs may be interesting in pharmaceutical formulations.

L-tryptophan is the precursor of the neurotransmitter 5hydroxitryptamine (5-HT, serotonin) and the neurohormone melatonin, both substances intrinsically linked to mood and sleep control [13]. The major biotransformation pathway of L-tryptophan lead to generation of kynurenines [14].

Several reports have been published on the antinociceptive effects of melatonin and 5-HT. However, the influence of 5-HT on 
pain control is controversial. Yaksh and Wilson [15] demonstrated that the intrathecal injection of serotonin in rats, rabbits and cats produces an elevation in nociceptive threshold measured by several behavioural methods. In the same work, the authors also demonstrated the blockage of the 5-HT antinociceptive effect by the receptor antagonist methysergide (mixed $5-\mathrm{HT}_{1}$ and $5-\mathrm{HT}_{2}$ ). However, Schmauss et al. [16] described no involvement of $5-\mathrm{HT}_{2}$ receptors on the antinociceptive activity of 5-HT administered by the intrathecal route on a tail flick test. Other studies have described the involvement of $5-\mathrm{HT}_{3}$ receptors on pain control. Bardin et al. [17] demonstrated that $5-\mathrm{HT}_{3}$ antagonism caused after treatment with tropisetron reverses 5-HT antinociceptive action. They also demonstrated that the intrathecal administration of a $5-\mathrm{HT}_{3}$ agonist has an antinociceptive effect.

All these studies used direct application of 5-HT on the central nervous system. This manipulation may flood others neurones where 5-HT is not a natural important neurotransmitter. Furthermore, this approach reduces the translational potential of 5-HT studies on pain.

The kynurenine pathway is the main route of L-tryptophan metabolism. This pathway leads to the generation of a metabolite family that includes anthranilic acid, xanthurenic acid, quinolinic acid and kynurenic acid (KYNA). All of these acids have neuro-active properties $[18,14]$. This pathway also generates deleterious metabolites, such as 3-hydroxykynurenine and 3-hydroxyanthranilic acid, that increase oxidative stress and can cause neuronal death. Quinolinic acid is an agonist of NMDA receptor and can exert excitotoxic effects [19]. In contrast, KYNA was described by Heyliger et al. [20] as an antinociceptive substance with the probable capacity to block glutamate receptors in thermal nociceptive tests [21].

Serotonin cannot cross the blood-brain-barrier but L-tryptophan is available as alimentary supplement being a highly safety substance that can be used as tool to increases the central 5-HT amount and studies the central 5-HT pathway on the control of pain. We report here that L-tryptophan in doses up to $200 \mathrm{mg} / \mathrm{kg}$ i.p. had no antinociceptive effect in the mouse abdominal writhing test when it was administered as the sole agent.

However, its position as precursor of 5-HT that is implicated as main neurotransmitter in the descending pain suppression pathway and several others biomolecules potentially involved in pain modulation made us study the interaction of this amino acid with dipyrone and paracetamol aiming to interfere on the different points of pain processing to increase the antinociceptive effect of these analgesics.

The general purpose of this study was to investigate the pharmacological interaction of L-tryptophan on the antinociceptive activity of the non-opioids analgesics in acute animal models of pain. To the best of our knowledge, no investigation has been conducted on the association of L-tryptophan with dipyrone or paracetamol.

\section{Materials \& methods}

\subsection{Animals}

Swiss mice (22-32 g, 5-12 animals per group) were used in this study. Animals were kept in a temperature-controlled room at $26^{\circ} \mathrm{C}$ with a 12-h light/dark cycle and maintained with food and water ad libitum. The experiments were approved in the Ethical Committee on Animal Research at Federal University of Ceará, Brazil (no. 63/2012). The study was conducted in accordance with the NIH Guide for the Care and Use of Laboratory (1985).

\subsection{Drugs}

L-tryptophan, kynurenic acid (Kyna), capsaicin, ruthenium red and luzindol were purchased from Sigma Chem. Co. ${ }^{\mathrm{TM}}$ (St. Louis, MO, USA). Acetic acid was purchased from Vetec Quimica Fina ${ }^{\mathrm{TM}}$ (São Paulo, São Paulo, Brazil), dipyrone and paracetamol were purchased from Medley Indústria Farmacêutica Ltd.

\subsection{Hematologic toxicity}

A cell blood counter was used to evaluate blood collected in micro tubes with $20 \mu \mathrm{L}$ of EDTA $(10 \mathrm{~g} / \mathrm{dL})$. After collection, the blood was maintained homogenised until analysis with a demi-automatic apparatus (Sysmex KX-21N-Roche). The differential quantification of leukocytes was performed utilizing panoptic staining in blood smears (Instant-Pro ${ }^{\circledR}-$ New Prov $^{\circledR}$ ).

\subsection{Open field test}

The ambulatory behavior was assessed in the open-field test as described previously (Archer, 1973). The open field is an acrylic box with transparent walls and black floor $(30 \mathrm{~cm} \times 30 \mathrm{~cm} \times 15 \mathrm{~cm})$, and its base is divided into 9 quadrants of equal diameter. The animals were treated with L-tryptophan (25; 50 or $100 \mathrm{mg} / \mathrm{kg}$ i.p.) or vehicle (Controls; $10 \mathrm{ml} / \mathrm{kg}$, p.o.) 30 min before being taken individually to the open field. The number of squares crossed with all paws (crossings) were counted in a 5 -min session.

\subsection{Abdominal writhing test}

This test was carried out according to the method described by Koster et al. [22]. An abdominal writhe consists of a contraction of the abdominal muscle together with a stretching of the hind limbs induced by an i.p. injection of acetic acid $(0.6 \%$ solution, $0.1 \mathrm{~mL} /$ $10 \mathrm{~g}$ ) as the nociceptive agent. These abdominal writhings were recorded as a pain response. The animals received i.p. injection of acetic acid $30 \mathrm{~min}$ after i.p. treatments with dipyrone, paracetamol or L-tryptophan. In the oral treatments the animals were submitted to the test $60 \mathrm{~min}$ after treatments with dipyrone, paracetamol, or L-tryptophan. Five minutes after acetic acid application, the abdominal writhes were counted over a 15 -min period.

\subsubsection{5-HT brain analysis}

The endogenous levels of 5-HT were assayed by reverse-phase high-performance liquid chromatography (HPLC) with electrochemical detection. Briefly, a C18 reverse phase column (Shimpack, CLC-ODS $150 £ 4.6 \mathrm{~mm}$; Shimadzu, Kyoto, Japan), an amperometric detector (Shimadzu, LECD-6A) and a liquid chromatography work station were used. The collected brains were stored at $-70{ }^{\circ} \mathrm{C}$ until the time for use (maximum of 2 weeks). The frozen tissue was weighed and homogenised in $10 \%(\mathrm{w} / \mathrm{v})$ of $0.1 \mathrm{M}$ perchloric acid. After centrifugation (14,000 rpm, $30 \mathrm{~min}), 20 \mathrm{ml}$ of the supernatant was injected into the chromatograph. The mobile phase (consisting of $15.7 \mathrm{~g}$ citric acid, $471.5 \mathrm{ml}$ twice-distilled water, $\mathrm{NaOH}$ sufficient to bring $\mathrm{pH}$ to $7.0,3.78 \mathrm{mg}$ octyl sodium sulphate, $20 \mathrm{ml}$ acetonitrile and $10 \mathrm{ml}$ tetrahydrofuran) was used at a flow rate of $0.6 \mathrm{ml} / \mathrm{min}$. The oxidation potential was fixed at $0.85 \mathrm{~V}$ using a glassy carbon electrode and an $\mathrm{Ag} / \mathrm{AgCl}$ reference electrode. The peak areas of the external standards were used to quantify the sample peaks. The values obtained were expressed as $\mu \mathrm{mol} / \mathrm{g}$ of tissue. In these analysis the groups were compared by ANOVA followed by Newman-Keuls multiple comparison test. 


\subsection{Protocol}

Dose-response curves for the antinociceptive effect of dipyrone or paracetamol, were obtained using 5-10 animals at each of at least four doses. The drugs were administered by oral or intraperitoneal route. A least-squares non-linear regression analysis of the $\log$ dose-response curves allowed the calculation of the dose that produced $50 \%$ of antinociception $\left(E_{50}\right)$ for each drug. Dose-response curves were also obtained for the oral coadministration of L-tryptophan with dipyrone or paracetamol in fixed ratio combinations by gavage (ratio values given in Table 1). Dose-response curves for the combination of L-tryptophan with dipyrone or paracetamol administered intraperitoneally were obtained with the same scheme (ratio values given in Table 1 ) but in this case the L-tryptophan was injected $30 \mathrm{~min}$ prior to i.p. injection of dipyrone or paracetamol. The construction of dose-response curves for Kyna i.p. or for the combination of Kyna with dipyrone or paracetamol were performed using the same mode previously described (ratio values given in Table 2) but in this case kyna was injected 15 min prior to i.p injection of dipyrone or paracetamol. The $\mathrm{ED}_{50} \mathrm{~S}$ of isolated treatment with dipyrone or paracetamol were compared with respective $\mathrm{ED}_{50} \mathrm{~S}$ of combined treatment with L-tryptophan. The comparisons were made by ANOVA (extra sum-of-squares $F$ test). Data are expressed in the graphs as percentage of antinociception (antinociception \%) calculated in comparison with respective vehicle-treated group (Control; CTRL) of each experiment \pm Standard Error of Mean (SEM).

Isobolographic analysis was used to determine interactions between kyna and dipyrone or paracetamol. The method has been described previously in detail [23]. Supra-additivity or synergistic effect is defined as the effect of a drug combination that is higher and statistically different $\left(\mathrm{ED}_{50}\right.$ significantly lower) than the theoretically calculated equieffect $\left(E_{50}\right)$ of a drug combination with the same proportions. Theoretical $E_{50} \mathrm{~S}$ were calculated $\left(\right.$ Add $=(f) \mathrm{ED}_{50}$, Dipyrone or Paracetamol $+(1-f) \mathrm{ED}_{50}$, Kyna, where $f$ is the fraction of dipyrone or paracetamol) and the statistical comparisons were made by $t$-test, the errors were estimate similarly to described by Raffa et al. [24]. If the $\mathrm{ED}_{50} \mathrm{~S}$ are not statistically different, the effect of the combination is additive and additivity means that each constituent contributes with its own potency to the total effect. The interaction index was calculated as experimental $\mathrm{ED}_{50}$ /theoretical $\mathrm{ED}_{50}$. If the value is close to 1, the interaction is additive. Values lower than 1 are an indication of the magnitude of supra-additive or synergistic interactions and values higher than 1 correspond to sub-additive or antagonistic interactions [25,23].

On the graph, the straight diagonal line indicates the line of additivity, where there is no synergism at the $\mathrm{ED}_{50}$ values and the location of the combination points on the left (below) side of the additive line indicates synergistic interactions [26-28].

On the assessment of melatonin receptors participation, to block the melatonin receptors, luzindol ( $10 \mathrm{mg} / \mathrm{kg}$, i.p.) was administered 15 min before L-tryptophan (i.p.) to the group treated with L-tryptophan before non-antinociceptive dose of dipyrone (i.p.) (luzindol + L-trytophan + dipyrone). In order to evaluate the involvement of 5-HT synthesis, other experiment was conducted utilizing para-chlorophenylalanine (PCPA) for depletion of 5-HT levels. The animals received PCPA (100 mg/kg, i.p.) once a day over 3 days preceding the experimental day as well as $3 \mathrm{~h}$ before the experimental procedure. In these analysis the groups were compared by ANOVA followed by Newman-Keuls multiple comparison test.

\section{Results}

\subsection{Haematological toxicity}

There were no significant differences in the hematologic parameters analysed (neutrophils, eosinophils, monocytes and lymphocytes) between the groups treated with non-opioids analgesics, L-tryptophan or any combination.

\subsection{Open field}

There were no significant differences in the number of crossing between the groups in this test. Controls (treated with vehicle $10 \mathrm{~mL} / \mathrm{kg}$, i.p.): 20.50 (14-28); L-tryptophan 100,50 or $25 \mathrm{mg} / \mathrm{kg}$, i.p.: $19.00(14-31) ; 20.25(12-30) ; 19.30$ (22-30), respectively. Data is described as mean with minimum and maximum number of crossing. This suggests no interference on the spontaneous locomotor activity of L-tryptophan.

\subsection{L-tryptophan}

As shown in the Fig. 1 the treatment with L-tryptophan both orally (Fig. 1A) and by intraperitoneal route (Fig. 1B) showed no antinociceptive effect as sole agent.

\subsection{L-tryptophan and dipyrone}

Dipyrone was administered in four doses as the sole agent by oral route and in six doses by i.p. route and exhibited significant antinociceptive action and marked dose dependence with $\mathrm{ED}_{50}$ : $128.7 \mathrm{mg} / \mathrm{kg}$ (CI 95\%: 92.78-178.6) and $91.20 \mathrm{mg} / \mathrm{kg}$

Table 1

ED50 values and 95\% CI for the antinociceptive effect of dipyrone and paracetamol isolated and in combination with L-tryptophan in the writhing test of mice.

\begin{tabular}{llll}
\hline Drug & Ratio & via & ED $_{50} \mathrm{mg} / \mathrm{kg}(\mathrm{CI} 95 \%)$ \\
\hline Dipyrone & - & p.o. & $128.7(92.78-178.6)$ \\
Paracetamol & - & p.o. & $308.1(256.1-370.8)$ \\
Dipyrone & - & i.p. & $91.20(77.39-95.78)$ \\
Paracetamol & - & i.p. & $96.18(76.23-121.3)$ \\
Combination & & & \\
\hline L-tryp + Dipyrone & $1: 1.4$ & p.o. & $33.30^{*}(28.05-39.54)$ \\
L-tryp + Paracetamol & $1: 1.5$ & p.o. & $50.99^{*}(41.96-61.96)$ \\
L-tryp + Dipyrone & $1: 2$ & i.p. & $18.07^{\gamma}(13.25-24.67)$ \\
L-tryp + Dipyrone & $1: 1$ & i.p. & $31.72^{\gamma}(23.10-43.56)$ \\
L-tryp + Paracetamol & $1: 4.12$ & i.p. & $47.30^{\gamma}(34.00-65.82)$ \\
\hline
\end{tabular}

(ANOVA - extra sum-of-squares $F$ test).

$p<0.001$ vs. isolated treatment (p.o.)

$\gamma p<0.001$ vs. isolated treatment (i.p.). 
Table 2

Theoretical and experimental $\mathrm{ED}_{50}$ values with $95 \% \mathrm{CI}$ for combinations of dipyrone or paracetamol with kyna in the writhing test of mice.

\begin{tabular}{|c|c|c|c|c|c|}
\hline Drug & Via & & $\mathrm{ED}_{50} \mathrm{mg} / \mathrm{kg}(\mathrm{Cl} 95 \%)$ & & \\
\hline Dipyrone & i.p. & & $91.20(77.39-95.78)$ & & \\
\hline Paracetamol & i.p. & & $96.18(76.23-121.3)$ & & \\
\hline Kynurenic acid & i.p. & & $19.51(17.88-21.30)$ & & \\
\hline Combination & Via & Ratio & $\mathrm{ED}_{50} \mathrm{mg} / \mathrm{kg}(\mathrm{Cl} 95 \%)$ & & Interaction index \\
\hline \multirow[t]{2}{*}{ Kyna + dipyrone } & i.p. & $1: 2$ & Theoretical & Experimental & \\
\hline & & & $\overline{60.19(51.07-63.21)}$ & $4.34^{*}(3.74-5.03)$ & 0.072 \\
\hline Kyna + paracetamol & i.p. & $1: 4.05$ & $77.13(61.13-97.27)$ & $25.47^{*}(18.66-34.77)$ & 0.330 \\
\hline
\end{tabular}

${ }^{*} p<0.05$ vs. Theoretical values $(t$-test).
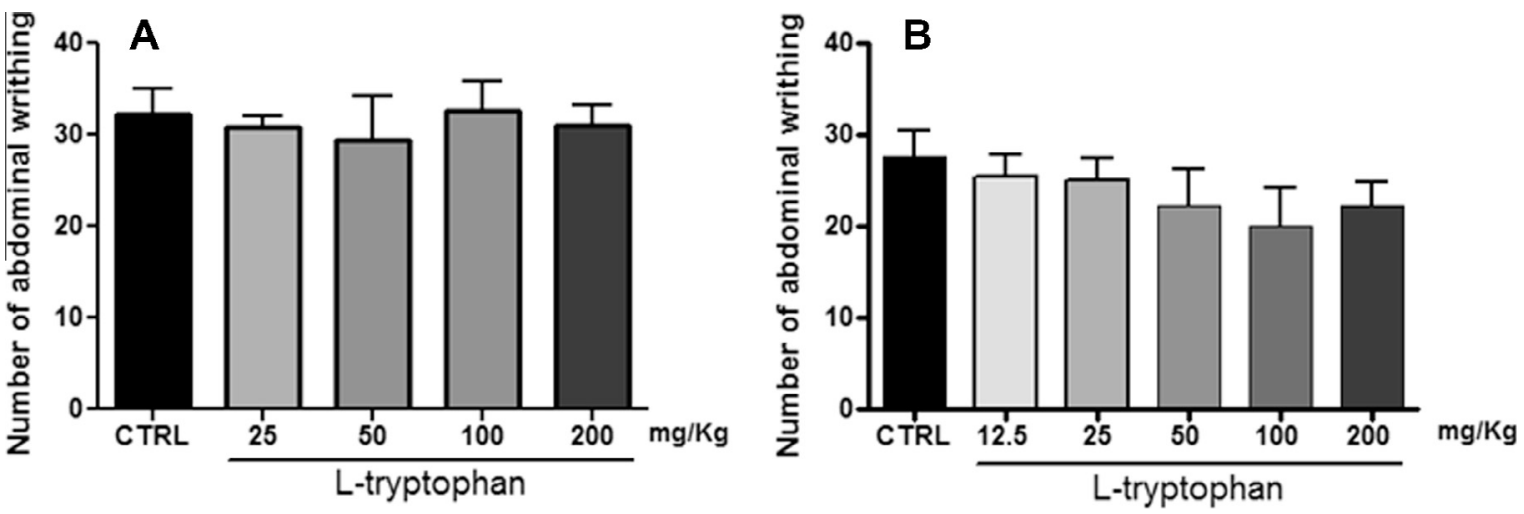


after both orally (A) or i.p. treatments (B). One-way ANOVA followed by Student-Neuman-Keuls post hoc.


- Par
- Par 4.12:1 L-tryp

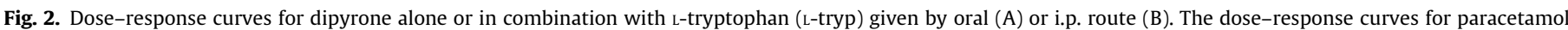




statistically* different from the respective isolated treatment (dipyrone or paracetamol). Data are expressed as percentage of antinociception \pm SEM. *(ANOVA, $p<0.05$ ).

(CI 95\%: 77.39-95.78) for the oral and i.p. route, respectively (Fig. 2A and B; Table 1). As cited previously L-tryptophan, in doses up to $200 \mathrm{mg} / \mathrm{kg}$ i.p. or oral, produced no antinociceptive effect compared with vehicle treated animals (CTRL).
Combined treatments of L-tryptophan and dipyrone would expect to have a dose-response relation theoretically identical to the response of the active agent alone. When the combination of L-tryptophan and dipyrone in a 1:1.4 ratio or $1: 1$ ratio by oral route 
and $1: 2$ ratio by i.p. route were tested it also exhibited significant dose dependence analgesic activity and a pronounced potency enhancement as indicated by the reduced $E_{50} \mathrm{~S}$ of $33.30 \mathrm{mg} /$ $\mathrm{kg}^{*}(28.05-39.54) ; \quad 31.72 \mathrm{mg} / \mathrm{kg}^{*}(\mathrm{Cl} \quad 95 \%$ : $23.10-43.56)$ or $18.07 \mathrm{mg} / \mathrm{kg}^{*}$ (CI 95\%: $\left.13.25-24.67\right)$, for treatments made in oral or i.p. route, respectively. These results strongly suggest a synergic interaction between the substances. Results are shown in the Fig. $2 \mathrm{~A}$ and $\mathrm{B}$ and summarized on Table $1 .{ }^{*} p<0.001$ vs. sole active drug.

\subsection{L-tryptophan and paracetamol}

Paracetamol was administered in five doses as the sole agent by oral route and in four doses by i.p. route and exhibited significant antinociceptive action and marked dose dependence with $\mathrm{ED}_{50}$ : $308.1 \mathrm{mg} / \mathrm{kg}$ (CI 95\%: 256.1-370.8) and $96.18 \mathrm{mg} / \mathrm{kg}$ (CI 95\%: 76.23-121.3) for the oral and i.p. route, respectively (Fig. $2 \mathrm{C}$ and 2D; Table 1).

When Paracetamol in combination with L-tryptophan, in a 1.5:1 or 4.12:1 ratio by oral or i.p. route respectively were tested, the combinations also exhibited significant dose dependence analgesic activity and a substantial potency enhancement as indicated by the reduced $\mathrm{ED}_{50} \mathrm{~S}$ of $50.99 * \mathrm{mg} / \mathrm{kg}(\mathrm{Cl} 95 \%: 41.96-61.96)$ or $47.30^{*} \mathrm{mg} /$ $\mathrm{kg}(34.00-65.82)$, for the treatments made by oral or i.p. route, respectively. These results strongly suggest a synergic interaction between the substances. Results are shown in the Fig. $2 \mathrm{C}$ and $\mathrm{D}$ and summarized on Table $1 .{ }^{*} p<0.001$ vs. sole active drug.

\subsection{Influence of 5-HT production on the synergistic effect}

L-tryptophan (i.p.) increased the total 5-HT concentration in the brain at doses of 25 and $100 \mathrm{mg} / \mathrm{kg}$ and PCPA decreased the 5-HT synthesis (Fig. 3A). The depletion of 5-HT blocked the synergism between L-tryptophan and non-antinociceptive dose of dipyrone $(50 \mathrm{mg} / \mathrm{kg}$ ) (Fig. 3B). This suggests the necessity of L-tryptophan be metabolised to 5 -HT to exhibit the synergism. $\psi^{*} p<0.05$ vs. vehicle treated group (CTRL), ANOVA, followed by Newman-Keuls multiple comparison test.

\subsection{Kyna}

Previous treatment with kynurenic acid at 18.75, 25 and $50 \mathrm{mg}$ / $\mathrm{kg}$ resulted in a reduced number of abdominal writhings compared to the control group * $(p<0.05)$ showing an important antinociceptive dose-related effect on the abdominal writhing test of kynurenic acid $\mathrm{ED}_{50}: 19.51 \mathrm{mg} / \mathrm{kg}$ (CI 95\%: 17.88-21.30) as shown in the Fig. 4A. ${ }^{*} p<0.05$ vs. vehicle treated group (CTRL), ANOVA, followed by Newman-Keuls multiple comparison test.

\subsection{Kyna and dipyrone}

This association shifts the dose-response curve of the antinociceptive effect of dipyrone to the left. The $\mathrm{ED}_{50}$ of dipyrone in association with kynurenic acid is significantly reduced when compared with the values of theoretical $\mathrm{ED}_{50}$ for simply additive effect of combination: $4.34^{*} \mathrm{mg} / \mathrm{kg}$ (CI 95\%: 3.74-5.03 - showed as the point under/left of the straight line) vs. 60.19 (51.07-63.21 - showed as the point on the straight line), respectively. ${ }^{*} p<0.001, t$-test. (Fig. 4B and Table 2).

\subsection{Kyna and Paracetamol}

Similar with dipyrone, the association between kyna and paracetamol shifts the dose-response curve of the antinociceptive effect of paracetamol to the left. The $\mathrm{ED}_{50}$ of paracetamol in association with kynurenic acid is significantly reduced when compared with the values of theoretical $\mathrm{ED}_{50}$ for simply additive effect of combination: $25.47^{*} \mathrm{mg} / \mathrm{kg}$ (CI 95\%: 18.66-34.77 showed as the point under/left of the straight line) vs. 77.13 (61.13-97.27 - showed as the point on the straight line), respectively. ${ }^{*} p<0.001, t$-test. (Fig. $4 \mathrm{C}$ and Table 2 ).

\subsection{Influence of Melatonin receptors on the synergistic effect}

Fig. 5 presents the influence of luzindol $10 \mathrm{mg} / \mathrm{kg}$ on the capacity of L-tryptophan to decrease the effective antinociceptive dose of dipyrone. The use of the melatonin-antagonist luzindol reduced the antinociceptive effect of drug combination L-tryptophan and dipyrone.

\section{Discussion}

To the best of our knowledge, this study is the first to describe the antinociceptive synergistic effect of combined treatment with L-tryptophan and dipyrone or paracetamol on abdominal writhing test. The pain mechanism underlying this model involves the release of several mediators, such as prostaglandins $E_{2}$ and $F_{2}$, $[29,30]$ histamine, bradykinin, 5-HT [31,32], and interleukins 1 and 8 [33]. Some substances, such as NSAIDs, sympathetic agonists, narcotics and natural anti-inflammatories, are able, via different mechanisms, to inhibit abdominal writhing in response to injection with acetic acid [34-39]. This multi-mediation is a desired characteristic to study synergistic phenomenon for the possibilities of the drugs studied interfere on different ways and then synergistic interaction could be elucidated.

Our results indicate that L-tryptophan at the doses used in this study did not exhibit an antinociceptive effect or reduced spontaneous locomotor activity. These results are in agreement with previous reports from Heyliger et al. [20] and Dennis \& Melzack [40] that described an antinociceptive effect of L-tryptophan after administration at higher doses than used in the present study (higher than $200 \mathrm{mg} / \mathrm{kg}$ ). Our results are also in agreement with previous studies of Curzon \& Marsden [41] that showed no alterations in motor activity after L-tryptophan $(150 \mathrm{mg} / \mathrm{kg})$ intraperitoneal injection. Gibbons et al. (1981)[42] verified that the ability to locomote on a rotating rod was not affected by L-tryptophan injections $(100 \mathrm{mg} / \mathrm{kg})$. Thereby, the effect of L-tryptophan on the nociceptive test is unlikely associated with loss of motor skills or any side effect attributed to higher doses of L-tryptophan in humans, especially taking into account that in the combinations utilized in this studies the highest dose of L-tryptophan was $50 \mathrm{mg} / \mathrm{kg}$.

The characterization of interaction between L-tryptophan and dipyrone or paracetamol was made taking account the zero efficacy of L-tryptophan on the abdominal writhing test. The relative position of curves and the statistical differences between $\mathrm{ED}_{50}$ after isolated treatment with dipyrone or paracetamol and after association with L-tryptophan indicates a synergic interaction between the drugs [25].

Especially relevant is the fact that L-tryptophan did not present antinociceptive activity as sole agent but presented a synergic activity with dipyrone or paracetamol in both oral and i.p. routes. We have shown that the L-tryptophan increases the 5-HT amount on the brains of animals at $25 \mathrm{mg} / \mathrm{kg}$ and $100 \mathrm{mg} / \mathrm{kg}$. These results suggest that, in contrast of central application of 5-HT, the increased 5-HT production on the central nervous system in consequence of L-tryptophan is not per se capable to induce antinociception.

However, the 5-HT depletion by PCPA antagonizes the synergistic effect of combination of L-tryptophan with dipyrone. Despite the increase in production of 5-HT not exhibit antinociceptive 





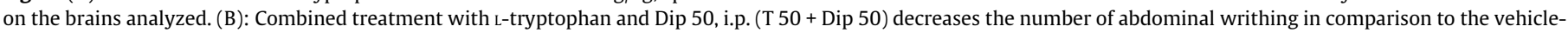

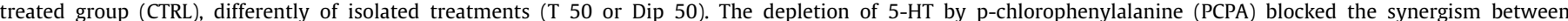



effect the increase in the amount of 5-HT is crucial for antinociceptive synergy between these drugs.

The majority of L-tryptophan is biotransformated by the kynurenine pathway, and one of these compounds is kynurenic acid (Kyna). Kyna is formed from kynurenine by kynurenine amino transferase. The compound has demonstrated several biological activities including glutamate receptor antagonism (NMDA and AMPA), antagonism of the $\alpha-7$ nicotinic cholinergic receptor and activation of the G-protein coupled receptor GPR35 [43-45].

Kyna has been described as being capable of inducing analgesia during hot-plate and tail-flick tests [20] and has anti-hyperalgesic activity following intrathecal administration [46]. Due to this, we could not discard the hypothesis that Kyna can influence the L-tryptophan synergic effect.

We examined the analgesic effect of Kyna. Our results demonstrated that doses higher than $18.75 \mathrm{mg} / \mathrm{kg}$ produced an analgesic effect during the abdominal writhing test; however, the lower doses did not produce an analgesic effect. It is noteworthy that this antinociceptive dose is much lower than the doses found by Heylinger et al. [20] during thermal nociceptive tests in rats. Furthermore, Kyna administration produces an antinociceptive synergistic effect with dipyrone and paracetamol. Having knowledge to the fact that kynurenine pathway represents a major route for the metabolism of tryptophan these results suggest that Kyna is, at least partly, involved in mediating the synergic effect of L-tryptophan with dipyrone or paracetamol.

L-tryptophan is a precursor of melatonin in the pituitary gland, and it has been shown that melatonin exerts an antinociceptive effect in several models of chemical or thermal nociception in mice. Furthermore, according to Mantovani et al. [50] melatonin administration produces a synergic analgesic effect with morphine and diazepam. This suggests a possible use as an adjunct medicine for the treatment of pain. Thus, to assess the involvement of melatonin receptors on the observed L-tryptophan effect, we blocked both melatonin receptors, MT1 and MT2.

MT1 and MT2 melatonin receptors play an important role in melatonin induced-antinociception in nociceptive [51] and neuropathic [52] pain models. Melatonin is able to inhibit forskolinstimulated cyclic AMP accumulation in rabbit cortex preparation [53] and chicken spinal cord explants [54]. Melatonin modifies $\mathrm{K}^{+}$and $\mathrm{Ca}^{2+}$ ion channel function. Besides, the inhibitory effects of melatonin are also extended to intracellular calcium, diacylglycerol and arachidonic acid derivative levels [56].

The interaction between L-tryptophan and dipyrone appears to involve the melatonin receptors, as pre-treatment with luzindol, an antagonist of the melatonin receptors, was able to partially block the effect of L-tryptophan on dipyrone antinociceptive activity. As showed by Yua et al. [57] luzindol does not affected the nociceptive threshold when given alone on the thermal nociceptive test, but antagonized significantly the antinociceptive effect induced by i.p. melatonin. Taken together, our result indicates that this synergism may involve the L-tryptophan biotransformation to melatonin and subsequently activation of melatonin receptors.

Our great interest in this work was study the synergism between L-tryptophan and dipyrone or paracetamol as well as the interaction of kyna and these analgesic agents utilizing a robust methodology and an in vivo approach. Therefore, others studies must be carried out to determine what is exactly the mechanism behind the synergism between L-tryptophan and dipyrone or paracetamol. 

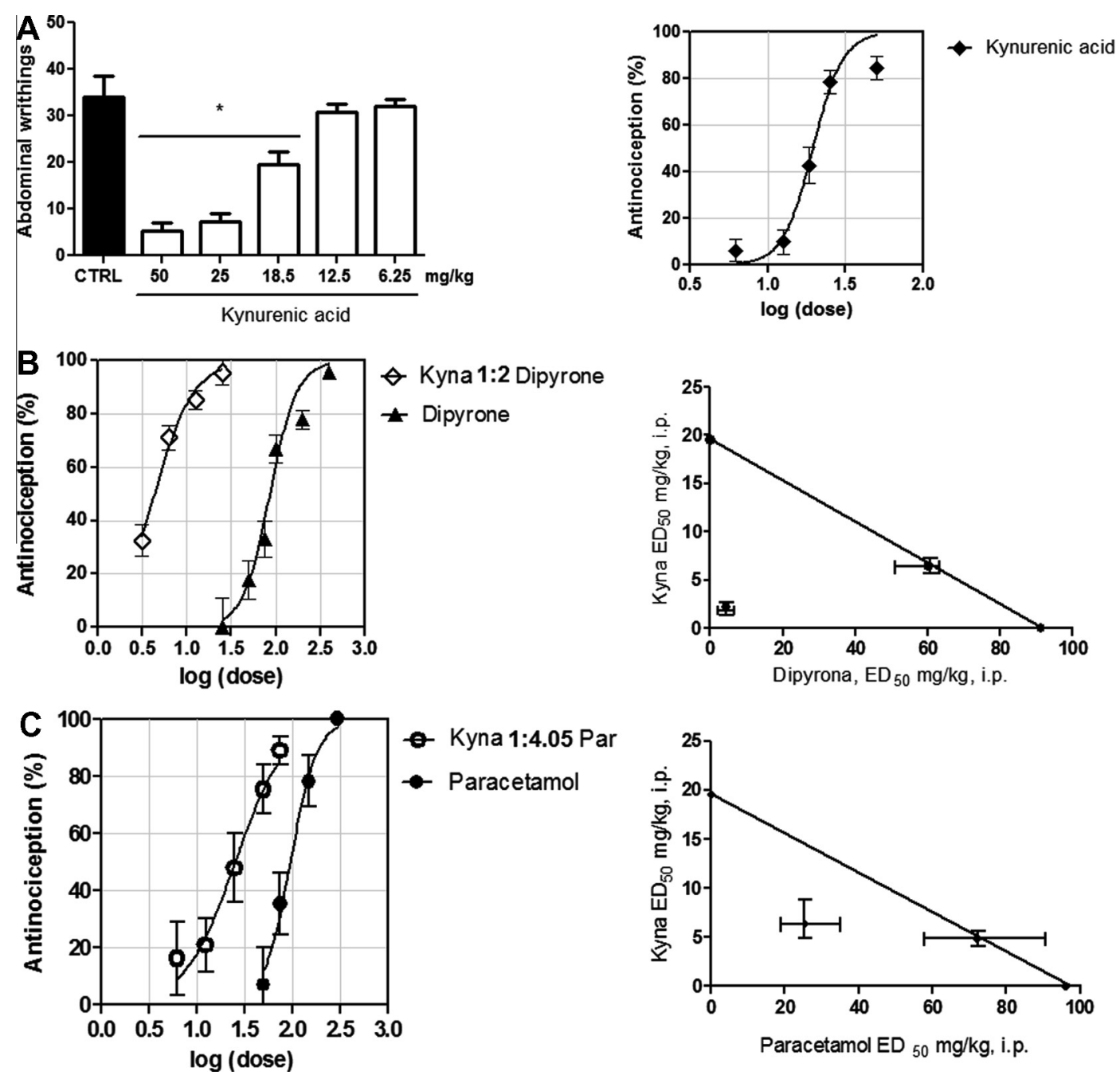

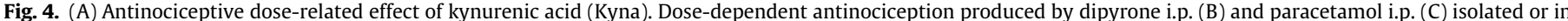



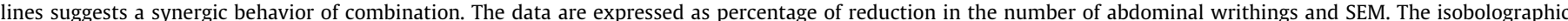

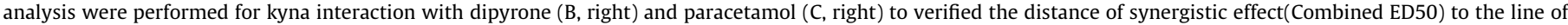
additivity and theoretical calculated values for ED50 (points on the diagonal line). ${ }^{*} p<0.05$ One-way ANOVA followed by Student-Neuman-Keuls post hoc.

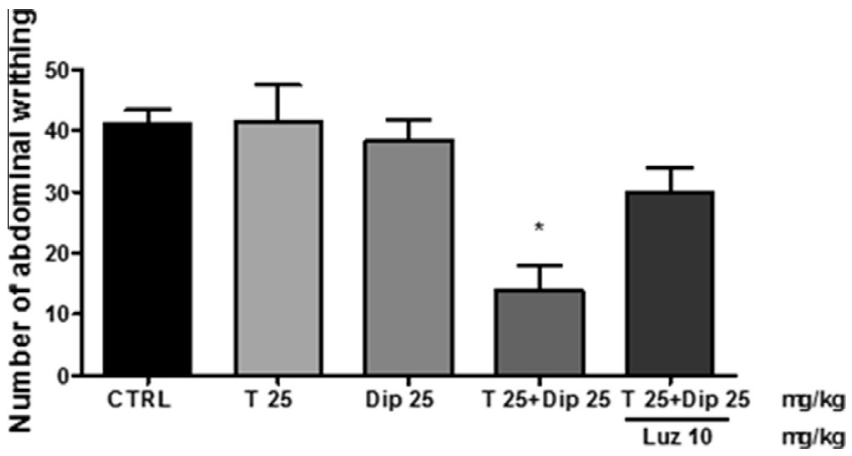

Fig. 5. Effect of melatonin antagonist luzindol on the L-tryptophan(T $25 \mathrm{mg} / \mathrm{kg}$ ) effect on the non-antinociceptive dose of dipyrone (Dip $25 \mathrm{mg} / \mathrm{kg}$ ). The previous i.p. administration of luzindol $10 \mathrm{mg} / \mathrm{kg}$ blocks partially the synergic ability of L-tryptophan $25 \mathrm{mg} / \mathrm{kg}$ i.p. + dipyrone i.p. $25 \mathrm{mg} / \mathrm{kg}$ treatment (Luzindol $10+\mathrm{T}$ 25 + Dip 25). Control group was treated with vehicle (CTRL). ${ }^{*} p<0.05$ vs. CTRL group, one-way ANOVA followed by Student-Neuman-Keuls.

The importance of these demonstrations is because synergism is an unpredictable event both in experimental models currently used for the study of pain, or in clinical practice. Tallarida et al.
[58] describes synergism between glucosamine and ibuprofen in the writhing model of mice induced by acetic acid, however the same work demonstrates that glucosamine blocks the antinociceptive effect of paracetamol in this model. Genovese et al. [59] demonstrated that the combined use of etanercept (Enbrel ${ }^{\circledR}$ ) and anakinra (Kineret ${ }^{\circledR}$ ), an immunoglobulin soluble receptor for Tumor Necrosis Factor (TNF) receptor and an antagonist of Interleukin-1 (IL-1), respectively, have no advantages compared to the alone use of each one of them for the treatment of patients with rheumatoid arthritis. Therefore, synergism cannot be previewed based only on the chief mechanism of action of a drug or by the interference on two points involved in the pathophysiology of a process.

Since the synergism is an unpredictable event, mainly when one of the drugs does not possess any efficacy, the present description turns especially interesting and may base subsequent clinical studies taking into account the knowledge and availability of substances studied here. In conclusion, our results demonstrate that L-tryptophan interacts synergistically with dipyrone and paracetamol. This effect is dependent on the biotransformation of L-tryptophan to 5-HT and involves kynurenic acid and melatonin receptors. 


\section{Conflict of interest}

There is no conflict of interest.

\section{Acknowledgements}

We are grateful to the following public institutions for financial support: the Brazilian National Council for Scientific and Technological Development (Conselho Nacional de Desenvolvimento Científico e Tecnológico - CNPq) and Coordination for the Improvement of Higher Level Personnel (Coordenação de Aperfeiçoamento de Pessoal de Nível Superior - CAPES).

\section{References}

[1] V.J. Dorr, J. Cook, Agranulocytosis and near fatal sepsis due to 'Mexican aspirin' (dipyrone), South. Med. J. 89 (1996) 612-614.

[2] J.E. Edwards, H.J. McQuay, Dipyrone and agranulocytosis: what is the risk?, Lancet 360 (2002) 1438

[3] K. Hedenmalm, O. Spigset, Agranulocytosis and other blood dyscrasias associated with dipyrone (metamizole), Eur. J. Clin. Pharmacol. 58 (2002) 265-274.

[4] G.W. Basak, J. Drozd-Sokołowska, W. Wiktor-Jedrzejczak, Update on the incidence of metamizole sodium-induced blood dyscrasias in Poland, J. Int. Med. Res. 2010 (38) (2010) 1374-1380.

[5] E.P. Maluf, Epidemiologia da anemia aplastica no Brasil, Doctorate thesis. Universidade de Sao Paulo, 1995.

[6] P. Martínez-Martín, E.J. Raffaelli, F. Titus, J. Despuig, Y.D. Fragoso, E. DíezTejedor, et al., Co-operative study group: efficacy and safety of metamizol vs. acetylsalicylic acid in patients with moderate episodic tension-type headache: a randomized, double-blind, placebo- and active-controlled, multicentre study, Cephalalgia 21 (2001) 604-610.

[7] J.Y. Mary, M. Guiguet, E. Baumelou, Drug use and aplastic anaemia: the French experience. French cooperative group for the epidemiological study of aplastic anaemia, Eur. J. Haemathol. 57 (1996) 35-41.

[8] F.C. Tulunay, H. Ergün, S.E. Gülmez, T. Ozbenli, M. Ozmenoğlu, C. Boz, et al., The efficacy and safety of dipyrone (Novalgin) tablets in the treatment of acute migraine attacks: a double-blind, cross-over, randomized, placebo-controlled multi-center study, Funct. Neurol. 19 (2004) 197-202.

[9] I.M. Boseñor, To use or not to use dipyrone? Or maybe, central station versus ER? That is the question..., Sao Paulo Med. J. 119 (2001) 190-191.

[10] N. Hamerschlak, E. Maluf, R. Pasquini, J. Eluf-Neto, F.R. Moreira, A.B. Cavalcanti, et al., Incidence of aplastic anemia and agranulocytosis in Latin America - the LATIN study, Sao Paulo Med. J. 123 (2005) 101-104.

[11] C.D. Souza, L.M. Barea, P.A. Kowacs, Y.D. Fragoso, Efficacy and tolerability of combined dipyrone, isometheptene and caffeine in the treatment of mild-tomoderate primary headache episodes, Expert Rev. Neurother. 12 (2012) 159 (Buckley \& Eddleston, 2005)

[12] N. Buckley, Paracetamol (acetaminophen) poisoning, Clin. Evid. 2007 (2007) 2101 ((online) Published online 2007 December 4. PMCID: PMC2943815).

[13] E.R.V. Rios, E.T. Venâncio, N.F.M. Rocha, D.J. Woods, S.M.M. Vasconcelos, Macedo, et al., Melatonin: pharmacological aspects and clinical trends, Int. J. Neurosci. 120 (2010) 583-590.

[14] J.C. Peters, Tryptophan nutrition and metabolism: an overview, Adv. Exp. Med. Biol. 294 (1991) 345-358.

[15] T.L. Yaksh, P.R. Wilson, Spinal serotonin terminal system mediates antinociception, J. Pharmacol. Exp. Ther. 208 (1979) 446-453.

[16] C. Schmauss, D.L. Hammond, J.W. Ochi, T.L. Yaksh, Pharmacological antagonism of the antinociceptive effects of serotonin in the rat spinal cord Eur. J. Pharmacol. 90 (1983) 349-357.

[17] L. Bardin, J. Lavarenne, A. Eschalier, Serotonin receptor subtypes involved in the spinal antinociceptive effect of 5-HT in rats, Pain 86 (2000) 11-18.

[18] I.P. Lapin, Stimulant and convulsive effects of kynurenines injected into brain ventricles in mice, J. Neural Transm. 42 (1978) 37-43.

[19] L.P. Carvalho, P. Bochet, J. Rossier, The endogenous agonist quinolinic acid and the non-endogenous homoquinolinic acid discriminate between NMDAR2 receptor subunits, Neurochem. Int. 28 (4) (1996) 445-452.

[20] S.O. Heyliger, C.B. Goodman, J.M. Ngong, K.F. Soliman, The analgesic effects of tryptophan and its metabolites in the rat, Pharmacol. Res. 38 (1998) 243-250.

[21] M. Bertolino, S. Vicini, E. Costa, Kynurenic acid inhibits the activation of kainic and N-methyl-D-aspartic acid-sensitive ionotropic receptors by a different mechanism, Neuropharmacology 28 (1998) 453-457.

[22] R. Koster, M. Anderson, J. De Beer, Acetic acid for analgesic screening, Fed. Proc. 18 (1959) 412-417.

[23] H.F. Miranda, M.M. Puig, J.C. Prieto, G. Pinardi, Synergism between paracetamol and nonsteroidal anti-inflammatory drugs in experimental acute pain, Pain $121(1-2)$ (2006) 22-28.

[24] R.B. Raffa, J.V. Pergolizzi, R.J.J. Tallarida, Analgesic combinations, J. Pain 11 (8) (2010) 701-709.

[25] R.J. Tallarida, Drug synergism: its detection and application, J. Pharmacol. Exp. Ther. 295 (2001) 546-551.
[26] F.K. Mohammad, K.H. Banan, B.K.H. Al-Baggou, A.S. Naser, Antinociception by metoclopramide, ketamine and their combinations in mice, Pharmacol. Rep. 64 (2012) 299-304.

[27] S.M. Tham, J.A. Angus, E.M. Tudor, C.E. Wright, Synergistic and additive interactions of the cannabinoid agonist CP 55,940 with $\mu$ opioid receptor and a2-adrenoceptor agonists in acute pain models in mice, Br. J. Pharm. 144 (2005) 875-884.

[28] R.J. Tallarida, Statistical analysis of drug combinations for synergism, Pain 49 (1992) 93-97.

[29] E. Elisabetsky, T.A. Amador, R.R. Albuquerque, D.S. Nunes, C. Carvalho, Analgesic activity of Psychotria colorata (wild ex Ret S) Muell Arg Alkaloids, J. Ethnopharmacol. 48 (1995) 77-83.

[30] J.W. Berkenkopf, B.M. Weichman, Production of prostacyclin in mice following intraperitoneal injection of acetic acid, phenylbenzoquinone and zymosan: its role in the writhing response, Prostaglandins 36 (1988) 693-709.

[31] R. Deraedt, S. Jouquey, J. Benzoni, M. Peterfalvi, Inhibition of prostaglandins biosynthesis by non-narcotic analgesic drugs, Arch. Int. Pharmacodyn. Ther. 224 (1976) 30-42.

[32] L. Guo, J. Li, H. Ye, R. Zheng, X.J. Hao, W.Y. Chen, et al., Anti-inflammatory and analgesic potency of carboxyamidotriazole, a tumoristatic agent, Zhongguo Yi Xue Ke Xue Yuan Xue Bao 325 (2009) 10-16.

[33] R.A. Ribeiro, M.L. Vale, S.M. Thomazzi, A.B. Paschoalato, S. Poole, S.H. Ferreira, et al., Involvement of resident macrophages and mast cells in the writhing nociceptive response induced by zymosan and acetic acid in mice, Eur. J. Pharmacol. 387 (2000) 111-118.

[34] H.O. Collier, L.C. Dinneen, C.A. Johnson, C. Schneider, The abdominal constriction response and its suppression by analgesic drugs in mouse, $\mathrm{Br}$. J. Pharmacol. Chemother. 32 (1968) 295-310.

[35] Y.A. Kolesnikov, I. Chereshnev, G.W. Pasternak, Analgesic synergy between topical lidocaine and topical opioids, J. Pharmacol. Exp. Ther. 295 (2000) 546551.

[36] R.M. Stepanovic-Petrovic, M.A. Tomic, S.M. Vuckovic, S. Paranos, N.D. Ugresic, M.S. Prostran, S. Milovanovic, B. Boskovic, The antinociceptive effects of anticonvulsants in a mouse visceral pain model, Anesth. Analg. 106 (2008) 1897-1903.

[37] A. Zanboori, E. Tamaddonfard, A. Mojtahedein, Effect of chlorpheniramine and ranitidine on the visceral nociception induced by acetic acid in rats: role of opioid system, Pak. J. Biol. Sci. 11 (2008) 2428-2432.

[38] G.A. Bentley, S.H. Newton, J. Starr, Studies on the antinociceptive action of ocagonist drugs and their interactions with opioid mechanisms, Br. J. Pharmacol. 79 (1983) 125-134.

[39] N.F. Rocha, E.R. Rios, A.M. Carvalho, G.S. Cerqueira, A.A. Lopes, L.K. Leal, et al., Anti-nociceptive and anti-inflammatory activities of (-)- $\alpha$-bisabolol in rodents, Naunyn Schmiedebergs Arch. Pharmacol. 384 (2011) 525-533.

[40] S.G. Dennis, R. Melzack, Pain modulation by 5-hydroxytryptaminergic agents and morphine as measured by three pain tests, Exp. Neurol. 69 (1980) 260270.

[41] G. Curzon, C.A. Marsden, The effect of L-tryptophan on changes in motor activity caused by parachlorophenylalanine, In: Proceedings of the B.P.S., 1973, 26th-27th, pp. 232-233.

[42] J.L. Gibbons, G.A. Barr, W.H. Bridger, S.F. Leibowitz, L-Tryptophan's effects on mouse killing, feeding, drinking, locomotion, and brain serotonin, Pharmacol. Biochem. Behav. 15 (2) (1981) 201-206.

[43] C. Hilmas, E.F. Pereira, M. Alkondon, A. Rassoulpour, R. Schwarcz, E.X. Albuquerque, The brain metabolite kynurenic acid inhibits alpha7 nicotinic receptor activity and increases non-alpha7 nicotinic receptor expression: physiopathological implications, J. Neurosci. 21 (2001) 7463-7473.

[44] T.W. Stone, J.I. Addae, The pharmacological manipulation of glutamate receptors and neuroprotection, Eur. J. Pharmacol. 447 (2002) 285-296.

[45] H. Wang, H. Liao, M. Ochani, M. Justiniani, X. Lin, L. Yang, et al., Cholinergic agonists inhibit HMGB1 release and improve survival in experimental sepsis, Nat. Med. 10 (2004) 1216-1221.

[46] G. Kekesi, G. Joo, E. Csullog, I. Dobos, W. Klimscha, K. Toth, et al., The antinociceptive effect of intrathecal kynurenic acid and its interaction with endomorphin-1 in rats, Eur. J. Pharmacol. 445 (2002) 93-96.

[50] M. Mantovani, M.P. Kaster, R. Pertile, J.B. Calixto, A.L. Rodrigues, A.R. Santos, Mechanisms involved in the antinociception caused by melatonin in mice, J. Pineal Res. 41 (2006) 382-389.

[51] C.X. Yu, C.B. Zhu, S.F. Xu, X.D. Cao, G.C. Wu, Selective MT melatonin receptor antagonist blocks melatonin-induced 2 antinociception in rats, Neurosci. Lett. 282 (3) (2000) 161-164.

[52] Ambriz-Tututi, Granados-Soto, Oral and spinal melatonin reduces tactile allodynia in rats via activation of MT2 and opioid receptors, Pain 132 (3) (2007) 273-280.

[53] B. Stankov, G. Biella, C. Panara, V. Lucini, S. Capsoni, J. Fauteck, B. Cozzi, F. Fraschini, Melatonin signal transduction and mechanism of action in the central nervous system: using the rabbit cortex as a model, Endocrinology 130 (4) (1992) 2152-2159.

[54] S.F. Pang, Q. Wan, G.M. Brown, Melatonin receptors in the spinal cord, Biol. Signals 6 (4-6) (1997) 272-283.

[56] M. Ambriz-Tututi, H.I. Rocha-González, S.L. Cruz, V. Granados-Soto, Melatonin: a hormone that modulates pain, Life Sci. 84 (15-16) (2009) 489-498.

[57] C.X. Yua, C. Zhua, S. Xua, X. Caoa, G. Wua, Selective MT2 melatonin receptor antagonist blocks melatonin-induced antinociception in rats, Neurosci. Lett. 282 (3) (2000) 161-164. 
[58] R.J. Tallarida, A. Cowan, R.B. Raffa, Antinociceptive synergy, additivity, and subadditivity with combinations of oral glucosamine plus nonopioid analgesics in mice, J. Pharmacol. Exp. Ther. 307 (2) (2003) 699-704.

anakinra in the treatment of patients with rheumatoid arthritis who have been treated unsuccessfully with methotrexate, Arthritis Rheum. 50 (5) (2004) $1412-1419$.

[59] M.C. Genovese, S. Cohen, L. Moreland, D. Lium, S. Robbins, R. Newmark, P. Bekker, 20000223 Study Group, Combination therapy with etanercept and 